University of Massachusetts Amherst

ScholarWorks@UMass Amherst

1996

\title{
Identification of selenium species in selenium- enriched garlic, onion and broccoli using high- performance ion chromatography with inductively coupled plasma mass spectrometry detection
}

$\mathrm{HH} \mathrm{Ge}$

XJ Cai

JF Tyson

PC Uden

ER Denoyer

See next page for additional authors

Follow this and additional works at: https://scholarworks.umass.edu/chem_faculty_pubs

Part of the Chemistry Commons

\section{Recommended Citation}

Ge, HH; Cai, XJ; Tyson, JF; Uden, PC; Denoyer, ER; and Block, E, "Identification of selenium species in selenium-enriched garlic, onion and broccoli using high-performance ion chromatography with inductively coupled plasma mass spectrometry detection" (1996). Analytical Communications. 1082.

Retrieved from https://scholarworks.umass.edu/chem_faculty_pubs/1082 
Authors

HH Ge, XJ Cai, JF Tyson, PC Uden, ER Denoyer, and E Block 


\title{
Identification of Selenium Species in Selenium-enriched Garlic, Onion and Broccoli Using High-Performance lon Chromatography With Inductively Coupled Plasma Mass Spectrometry Detection
}

\author{
Honghong Ge ${ }^{a}$, Xiao-Jia Cai ${ }^{a}$, Julian F. Tyson ${ }^{a},{ }^{*}$ Peter C. Uden, ${ }^{a}$ Eric R. \\ Denoyer $^{b}$, and Eric Block ${ }^{c}$ \\ a Department of Chemistry, Box 34510, University of Massachusetts, Amherst, \\ MA 01003-4510, USA \\ ${ }^{b}$ The Perkin-Elmer Corporation, 761 Main Ave., Norwalk, CT 06897-0215, \\ USA \\ c Department of Chemistry, State University of New York, Albany, NY 12222, \\ USA
}

\begin{abstract}
Six standard selenium species including selenocystine, methyl selenocysteine, selenite, selenomethionine, allyl selenocysteine and selenate have been separated by high-performance ion chromatography on a Hamilton PRPX-100 column and detected by ICP-MS. Selenium enriched vegetables were analysed. Five selenium species and several unknown peaks were detected.
\end{abstract}

The nutritional effects and possible toxicity of selenium on a biological system depend on different selenium forms and their quantitites. $^{1,2}$ Selenium compounds are dispersed throughout the environment by a variety of industrial, agricultural and natural processes. There is a growing interest in the speciation of selenium in different matrices, in order to gain an understanding of the selenium cycle and of selenium bioavailability in nature.

Chromatographic separation with element specific detection is clearly a candidate method for trace selenium speciation. ${ }^{3}$ Element specific detectors such as atomic absorption spectrometers and atomic emission spectrometers have been coupled to GC for the determination of volatile selenium species or derivatives, ${ }^{4-9}$ while ion-exchange, ion-pair and reversed-phase liquid chromatography have been used with derivatization for the separation and quantification of inorganic selenium species and selenoamino acids. ${ }^{10-19}$

In this work, an inductively coupled plasma mass spectrometer has been directly coupled to a high-performance ion chromatographic system. For the first time, six non-volatile selenium species were separated in a relatively short time. The compounds were selenite, selenate, selenocystine, methyl selenocysteine, allyl selenocysteine and selenomethionine. Several selenium-enriched vegetables were analysed, including garlic, onion and broccoli. Allium group vegetables tend to take up inorganic selenium followed by conversion to various organic forms, ${ }^{20-23}$ possibly including methyl selenocysteine and allyl selenocysteine. Five selenium species were identified in these vegetables and some unknown peaks were also observed.

\footnotetext{
* To whom correspondence should be addressed.
}

\section{Experimental}

\section{Sample Sources}

Standard selenomethionine, selenocystine and sodium selenate were purchased from the Sigma (St. Louis, MO, USA). Plasmagrade standard selenite solution was obtained from Spex Industries (Edison, NJ, USA). Standard methyl selenocysteine and allyl selenocysteine were obtained from Professor $\mathrm{H}$. Ganther, University of Wisconsin (Madison, WI, USA). Freezedried selenium-enriched plant samples were obtained from Dr. C. Ip, Roswell Park Cancer Institute (Buffalo, NY, USA). The plants were grown under standard nutrition conditions with addition of sodium selenate.

\section{Instrumentation}

The separation system consisted of a Waters M-6000 high pressure pump and a Hamilton PRPX-100 PEEK anion exchange column $(4.6 \mathrm{~mm} \times 150 \mathrm{~mm})$. A Perkin-Elmer SCIEX ELAN 5000 inductively coupled plasma mass spectrometer was used as the detector for which the operation parameter settings are shown in Table 1 . Polyethylene tubing $(30 \mathrm{~cm} \times 0.58 \mathrm{~mm}$ id) transferred the LC eluent into the spectrometer cross-flow nebulizer inlet. A Scott-type, double-pass spray chamber was used.

\section{Method}

The optimized mobile phase was $5 \mathrm{mmol} \mathrm{l}^{-1}$ ammonium citrate buffer at $\mathrm{pH} 4.8$ containing $2 \%$ methanol as an organic modifier. The mobile phase was delivered isocratically at $1 \mathrm{ml} \mathrm{min}^{-1}$. Selenium enriched plant samples studied include garlic samples

Table 1 Parameter settings for ICP-MS

\begin{tabular}{|c|c|}
\hline Forward If power/W & 1000 \\
\hline Plasma Ar flow $/ 1 \mathrm{~min}^{-1}$ & 15 \\
\hline Auxiliary Ar flow/l $\mathrm{min}^{-1}$ & 0.8 \\
\hline Carrier (nebulizer) Ar flow $/ \mathrm{min}^{-1}$ & $0.75-0.95$ \\
\hline Sampler and skimmer cones & $\mathrm{Ni}$ \\
\hline Scan mode & Peak hop \\
\hline Dwell time/ms & 100 \\
\hline Mass of selenium monitored & 82 \\
\hline
\end{tabular}


$\mathrm{A}$ and $\mathrm{B}$ (containing approximately 1000 and $100 \mathrm{ppm}$ total Se, respectively), an onion sample $C$ (containing approximately $100 \mathrm{ppm}$ total $\mathrm{Se}$ ), a broccoli sample $\mathrm{D}$ (containing approximately $300 \mathrm{ppm}$ total Se) and a natural garlic sample (estimated to contain approximately $0.02 \mathrm{ppm}$ total Se). Finely ground plant samples were accurately weighed (about $0.2 \mathrm{~g}$ ) into $15 \mathrm{ml}$ centrifuge tubes, and extracted with $4 \mathrm{ml}$ of $10 \%$ methanol in $0.2 \mathrm{~mol} \mathrm{l}^{-1}$ hydrochloric acid solution. ${ }^{23}$ The mixtures were sonicated for $1 \mathrm{~h}$ and centrifuged. The extracts were filtered through a $0.2 \mu \mathrm{m}$ polysulfone membrane filter after adjusting the $\mathrm{pH}$ to about 7.0 , and retained for analysis. Spike recovery experiments based on selenate were performed. Comparison of chromatographic peak profiles with those of reference analytes was also carried out.

\section{Results and Discussion}

Fig. 1 shows the chromatogram of six standard selenium species (250 ppb for each standard). Figs. 2, 3, 4 and 5 are chromatograms for garlic samples $\mathrm{A}$ and $\mathrm{B}$, and the onion and broccoli samples $\mathrm{C}$ and $\mathrm{D}$, respectively. Methyl selenocysteine, selenocystine, selenite, selenomethionine and selenate were observed in garlic sample A (1000 ppm Se), methyl selenocysteine being the predominant form of selenium observed. Selenocystine was found to be predominant in garlic sample B (100 ppm Se). At this stage it is not clear whether the peak

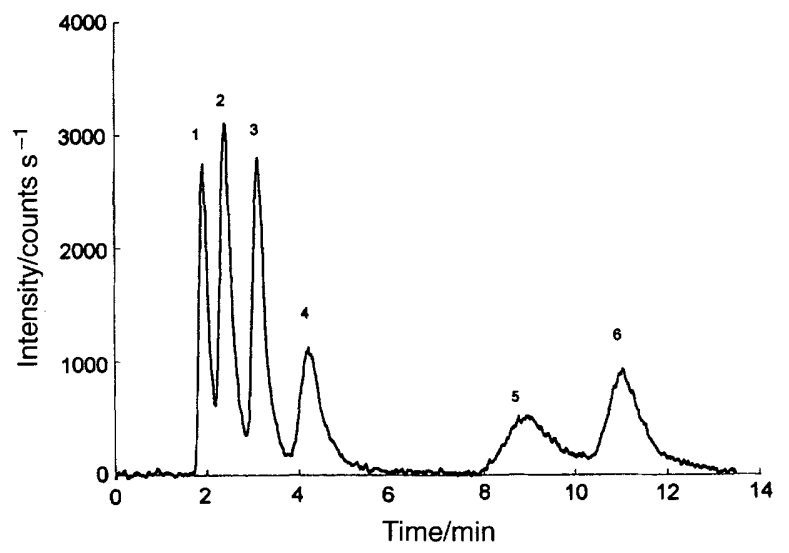

Fig. 1 Separation of six selenium standard compounds (1, selenocystine; 2 , methylselenocysteine; 3 , selenite; 4 , selenomethionine; 5 , allylselenocysteine; and 6 , selenate; $250 \mathrm{ppb}$ of Se for each standard) by high performance ion chromatography with ICP-MS detection.

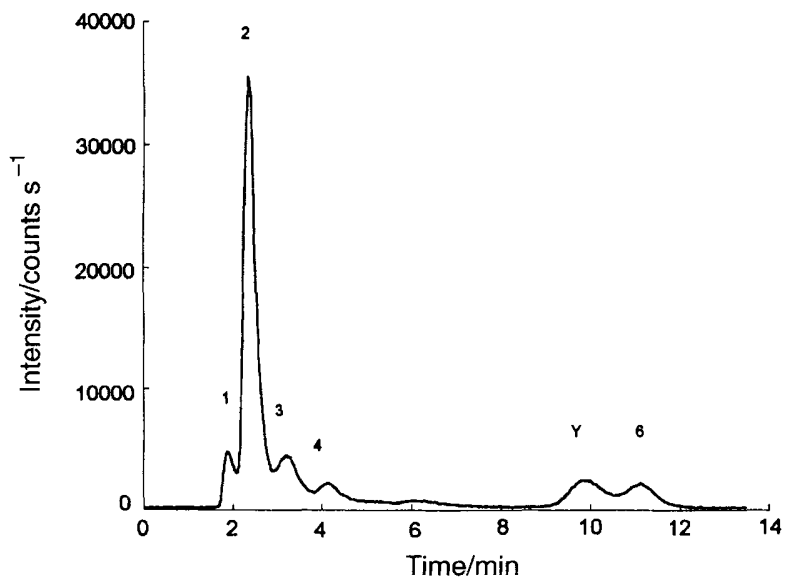

Fig. 2 Separation of compounds (1, selenocystine; 2, methylselenocysteine; 3 , selenite; 4 , selenomethionine; Y, unknown; and 6 , selenate) extracted from garlic sample A (approximately 1,000 ppm total Se). contribution to selenocystine is completely resolved from any other selenium-containing species eluted in the void volume. Methyl selenocysteine, selenocystine and selenomethionine were found in the onion sample while the two former amino acids together with selenite and selenate were found in the broccoli sample. There were three major unknown peaks observed in these samples, peak $X$ with 5.60 min retention time, peak $\mathrm{Y}$ with 10.06 min retention time and peak $\mathrm{Z}$ with 12.07 min retention time. Chromatographic comparison experiments

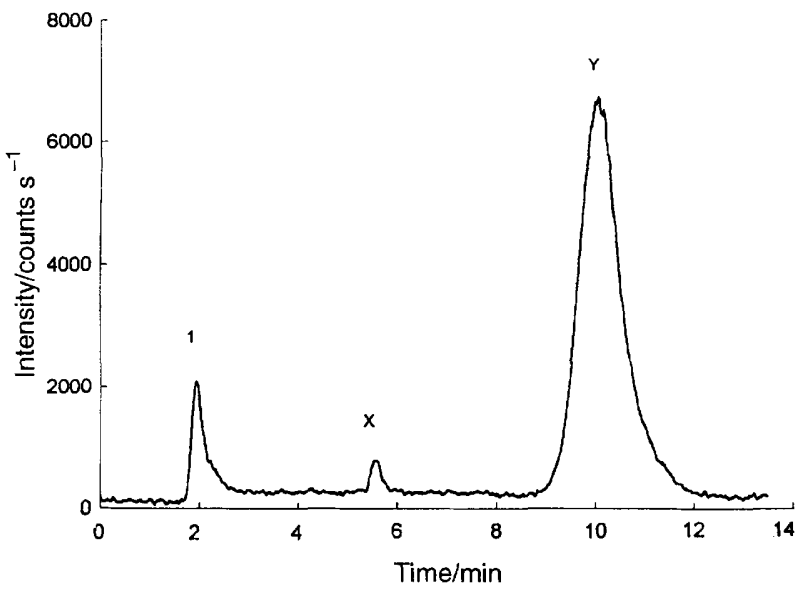

Fig. 3 Separation of compounds (1, selenocystine; X, unknown; and Y, unknown) extracted from garlic sample B (approximately $100 \mathrm{ppm}$ total Se).

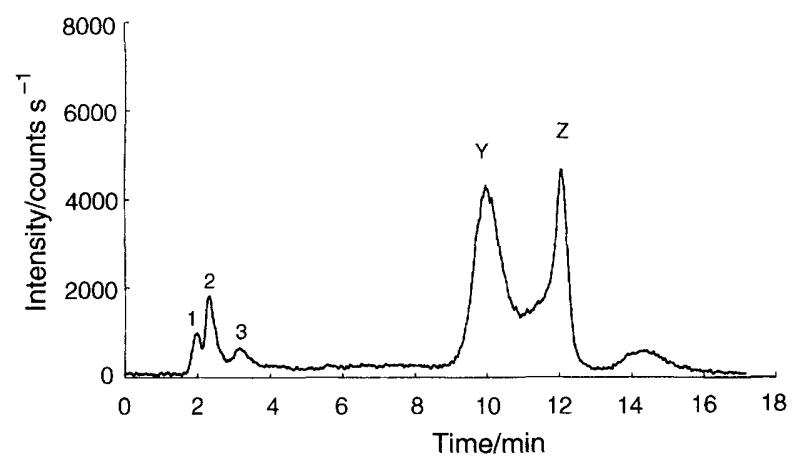

Fig. 4 Separation of selenium compounds (1, selenocystine; 2, methylselenocysteine; 3 , selenite; $\mathrm{Y}$, unknown; and $\mathrm{Z}$, unknown) extracted from onion (approximately $100 \mathrm{ppm}$ total $\mathrm{Se}$ ).

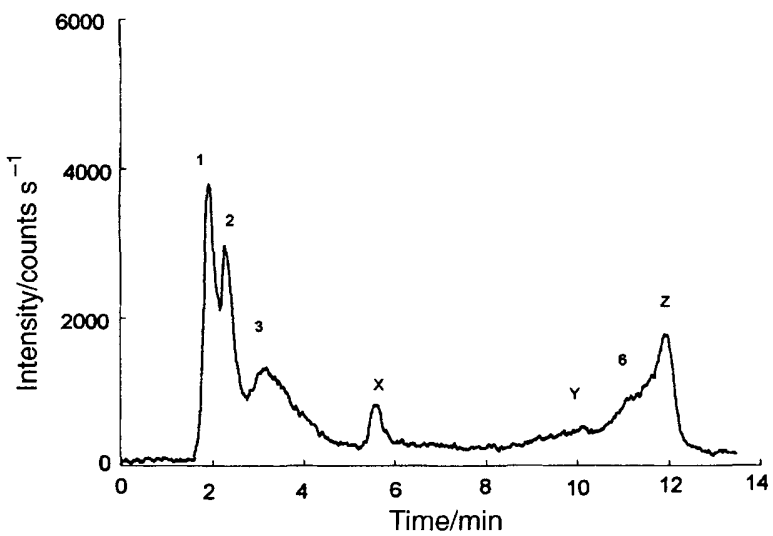

Fig. 5 Separation of selenium compounds (1, selenocystine; 2, methylselenocysteine; 3 , selenite; X, unknown; Y, unknown; 6 , selenate; and Z, unknown) extracted from broccoli (approximately $300 \mathrm{ppm}$ total Se). 
showed that none of these unknown peaks could be identified with any of the standards available. Selenate recovery from a freeze-dried garlic sample was $98 \pm 4 \%$. No selenium species were detected in the natural garlic sample $(0.02 \mathrm{ppm} \mathrm{Se})$, as the method does not have sufficient detection power.

The provision and maintenance of the ELAN 5000 spectrometer by the Perkin-Elmer Corporation is gratefully acknowledged.

\section{References}

1 Olivas, R. M., and Donard, O. F. X., Anal. Chim. Acta, 1994, 286, 357.

2 Kolbl, G., Kalcher, K., Irgolic, K., and Magee, R. J., Appl. Organomet. Chem., 1993, 7, 443.

3 Uden, P. C., Element-Specific Chromatographic Detection by Atomic Emission Spectroscopy, American Chemical Society Symposium Series No. 479, ACS, Washington DC 1992.

4 Cai, X., Uden, P. C., Block, E., Zhang, X., Quimby, B., and Sullivan, J. J., J. Agric. Food Chem., 1994, 42, 2081.

5 Jiang, G.-b., Ni, Z.-m., Zhang, L., Li, A., Han, H.-b., and Shan, X.-q., J. Anal. At. Spectrom., 1992, 7, 447.

6 D'Ulivo, A., and Papoff, P., J. Anal. At. Spectrom., 1986, 1, 479.

7 Jiang, S. G., Robberecht, H., and Adams, F., Appl. Organomet. Chem., 1989, 3, 99.

8 Cai, X., Uden, P. C., Block, E., Zhang, X., Quimby, B., and Sullivan, J. J., J. Agric. Food Chem, 1995, 43, 1754

9 Tanzer, D., and Heumann, K. G., Atmos. Environ. 1990, 24A, 3099.
10 Laborda, F., de Loos-Vollebregt, M. T. C., and de Galan, L., Spectrochim. Acta, Part B, 1992, 46, 1089.

11 Lafreniere, K. E., Fassel, V. A., and Eckel, D. E., Anal. Chem., 1987, 59, 879

12 Potin-Gautier, M., Boucharat, C., Astruc, A., and Astruc, M., Appl. Organomet. Chem., 1993, 7, 593

13 Sanz-Medel, A., Aizpun, B., Marchante, J. M., Segovia, E., Fernandez, M. L., and Blanco, E., J. Chromatogr., 1994, 683, 233.

14 Schlegel, D., Mattusch, J., and Dittrich, K., J. Chromatogr., 1994 683, 261.

15 Matni, G., Azani, R., Van Calsteren, M. R., Bissonnette, M. C., and Blais, J. S., Analyst, 1995, 120, 395

16 Colon, L. A., and Barry, E. F., J. High Res. Chromatogr., 1991, 14, 609.

17 Huyghues-Despointes, A., Momplaisir, G. M., Blais, J. S., and Marshall, W. D., Chromatographia, 1991, 31, 481.

18 Blaise, J.-S., Huyghues-Despointes, A., Momplaisir, G. M., and Marshall, W. D., J. Anal. At. Spectrom., 1991, 6, 225.

19 Laborda, F., Chakraborti, D., Mir, J. M., and Castillo, J. R., J. Anal. At. Spectrom., 1993, 8, 643.

20 Banuelos, G. S., Dyer, D., Ahmad, R., Ismail, S., Raut, R. N., and Dagar, J. C., U.S. J. Soil Water Conserv., 1993, 48, 530

21 Wang, W., Tang, J., and Peng, A., Shengwu HuaXue Zazhi, 1989, 5 229; Chem. Abstr., 1989, 111, 95847d.

22 Yang, M., Wang, K., Gao, L., Han, Y., Lu, J., and Zou, T., J. Chin Pharm. Sci., 1992, 1, 28; Chem. Abstr., 1993, 118, 77092u.

23 Ip, C., and Lisk, D. J., Carcinogenesis (London), 1994, 15, 1881. 